\title{
Training Needs of Buffalo Farmers in Madhepura District of Bihar, India
}

\author{
Ankush Bharti ${ }^{1 *}$, Debasis Ganguli ${ }^{1}$, Arunasis Goswami ${ }^{1}$ and Pankaj Kumar ${ }^{2}$ \\ ${ }^{1}$ Department of Veterinary and Animal Husbandry Extension Education, West Bengal \\ University of Animal and fishery sciences, Kolkata- 700037, India \\ ${ }^{2}$ Bihar Veterinary College, Patna, India \\ *Corresponding
}

\section{A B S T R A C T}

\begin{tabular}{|l|}
\hline Ke y w o r d s \\
Buffalo farmer, \\
Training, \\
Madhepura, \\
Bihar
\end{tabular}

The training can be more effective and significant when analysis of training needs prior to the beginning of training programmes and imparting knowledge according to the needs of the farmers. The present study was conducted in the Madhepura District of Bihar with the purpose of identifying training needs of buffalo farmers. Seven different farming practices were undertaken for study as farmers training needs. Under each major component, specific and relevant training need items were collected and systematically incorporated into the structured interview schedule. The findings of study revealed that the 72 per cent of the respondents conveyed their opinion regarding training needs about proper housing management as most needed followed by feeding management practices of animal (70\%), nutritional management $(61 \%)$, general management of animal $(57 \%)$, health care and management practices (55\%), proper milking practices $(33 \%)$ and breeding management practices (29\%). Study also depicted overall training needs along with various factors relating to training needs.

\section{Introduction}

India is predominantly an agrarian country with animal husbandry playing significant role in accelerating the growth of rural economy and thus it is a backbone of agricultural based farming sector. Out of the total agricultural GDP of India, livestock sector contributed about 27.25 per cent during $12^{\text {th }}$ five year plan, 2012-13, of which maximum contribution was from dairy sector (Anonymous, 2014). Training is very much essential for rural dairy farmers which help to improve trainees skill, desired attitude and values required for the work. According to Lyntonn and Pareek (1990), training consists of well organized opportunities for participants to acquire necessary understanding and skill. Farmers training mainly takes place outside of formal learning institutions and generally directed towards improving their job efficiency in respective field. Farmers training geared towards adult learning. In order to make any training meaningful and effective, it is important to identify the training needs of the farmers. Training need is the gap between 
'what is' and 'what ought to be'. Based on this, suitable training model can be developed so that the appropriate training is given to the right people, in right form, at right time so that his/her degree of productivity and profitability can be achieved. Davis and Rylance (2005) suggested that training focused on enterprise skills, such as market analysis, distribution and business management, would support small scale farmers in identifying the technologies that would encourage them most and would help them to participate in agricultural innovation. Needs of training is progressively realized all over the world.

\section{Materials and Methods}

The present study was conducted in Madhepura district of Bihar, as the buffalo population was highest as per $19^{\text {th }}$ livestock census in Bihar. Two blocks namely Madhepura and Kumarkhand was purposively selected as these two blocks had largest population of buffalo in Madhepura district. From each blocks, 5 villages were selected randomly. Therefore, a total of 10 villages were selected for the present study. From each village 10 buffalo farmers were randomly selected, thus forming a total sample size of 100 . Respondents were interviewed personally with the help of pre-structured schedule developed for the study. In the present study the training needs of buffalo farmers were categorized into seven broad categories for the study viz, feeding practices, health care and management practices, housing management, general management, nutritional management, breeding management and proper milking practices of animal. Under each major component, specific and relevant training need practices were collected through different review of literature, district extension personal, experts, teachers, buffalo farmers as well as investigators own field experience and were systematically incorporated in the interview schedule. The structured schedules were administered to the respondents for data collection. In this regard buffalo farmers were requested to give their response against each specified question and by investigators there training needs were categorized as most needed, needed or not needed based on their perceived needs regarding training for further improvement in their farming system and livelihood. Each major training (7 practices) needs comprises of several sub heads, thus operation making total of 42 training needs practices in selected area for study purpose. The statistical method used for data analysis is frequency.

\section{Results and Discussion}

\section{Training needs in feeding practices}

Efficient production requires efficient feeding management. Adequate feeding will ensure that animal attains desired body weight, produce more milk and remains healthy. As feeding alone accounts for around 70 percent of expenses incurred for dairying. Our findings observed that majority of the farmers (96\%) needed training in balance ration preparation, followed by total dry matter feeding (83\%), calf feeding (74\%) and adequate provision of water $(72 \%)$. Regarding pregnant animal feeding 57 percent of the respondent farmers expressed their training need as most needed followed by 43 percent needed and no respondents were found full knowledge of proper feeding to their animal during pregnancy (Table 1). It was found that majority of respondents expressed their need about feeding practices as 'most needed' training, this might be due to their will to know the ways to enhance milk yield, keep animal healthy, proper feeding at cheaper rates and to improve reproductive outcome, not only in terms of number of offspring born, but also in terms of physiological well-being and viability which is the key to progress in the dairy enterprise particularly when effective 
cost of feed is increasing day by day, with not so much corresponding increase in milk rates. These finding were supported by Pharate et al., (2010) and Patil et al., (2009).

\section{Training needs in health care and management practices}

Health management ensures the optimal care and well being of animal and reduces losses in productivity caused by diseases and management errors. The chronological training needs felt by the buffalo farmers in adoption of improved buffalo farming practices presented in the Table 2. Among several training needs, as regard to health care and management practices, the majority of respondents were of the opinion that found in the identification of common infectious diseases $(82 \%)$ was the most needed training area followed by vaccination schedule $(65 \%)$, deworming schedule $(61 \%)$, Precaution during pregnancy $(60 \%)$, management of pregnant animal before parturition (50\%) and after parturition (44\%), where as in case of animal protection in adverse environment 40 percent respondents conveyed their opinion as most needed followed by 44 percent needed and 16 percent as not needed. Majority of the respondents expressed their training need about health care and management practices as 'most needed' training, this might be due to lack of technical knowledge about health and clinical aspects, heavy economic losses because of diseases and unavailability of timely veterinary services in remote and rural areas in emergency situations. These findings are supported by Meena (1994) and Patil et al., (2009).

Training needs in housing management: A well designed house will give opportunity to the buffalo owner for the further development, easy to clean, reduces feed cost and easier manure handling and or byproducts. Under principles of housing viz, space required for different age group of animal, housing in different season, appropriate ventilation provision, dimension and direction of shed and day to day housing activities were considered. The results in Table 3 depicts that both principles of housing $(75 \%)$ and shed cleaning $(70 \%)$ was the most needed training area for the respondent buffalo farmers. These findings are in line with the findings of Patil et al., (2009).

\section{Training needs in general management}

Regarding training needs in general management practices of buffalo the majority of farmers were found to be require training in hygienic milk production $(70 \%)$ followed by calf care $(60 \%)$, navel cord cutting after birth of offspring (57\%), care of animal before and after parturition $(50 \%)$ and pregnant animal care $(47 \%)$.

Majority of the respondents were found to have most needed training, this might be due to their desire of knowing the advance way of practicing different managemental practices (Table 4). Present findings are supported by Patil et al., (2009).

\section{Training needs in nutritional management}

The proper feeding of animal at different age group (82\%) was indicated as most needed training area followed by importance of hygienic feeding (58\%), importance of colostrums feeding (52\%) and importance of mineral mixture in feed $(51 \%)$. It was also reported that very few i.e. only 3 per cent of respondents did not required training in the field of feeding of animals at different age group of animals (Table 5). This might be due to their regular consultancy with veterinarian or any expert in the field of feed formulator and variation was also found in the field of practicing mineral mixture at proper ratio to 
the animal this may be due to economic status of the farmer. These findings are agreed with the findings of Pharate et al., (2010).

\section{Training needs in breeding management practices}

The results in Table 6 identifies that only 12 percent of respondent famers perceived their training needs regarding heat detection in animal as most needed followed by gestation period only 7 percent. This indicates that majority of respondents easily identifies buffalo's behavior and other observable symptoms like mounting, mucous discharge, grunting etc. during heat. These findings are in line with the findings of Sah et al., (2002). It was also found that majority of farmers $(54 \%)$ were under most needed training area in knowing importance of Artificial insemination followed by benefits of regular pregnancy diagnosis (49\%).

\section{Training needs in milking practices}

Milk is the main product of cattle and buffalo farm enterprises, produced basically as food for human consumption. Therefore, buffalo farmer as well as dairy farmer must aim at maximizing on milk output from his/her animal herd. At the same time farmer must ensured that milk is produced in clean and hygienic condition so that it is fit for human consumption. The majority of the respondents (79\%) required training in proper udder wash before milking of their buffalo followed by fixed time interval between consecutive milking (45\%) and properly hind quarter wash prior to milking (38\%). It was also found that majority of the respondents $(50 \%)$ had medium level of knowledge regarding first strip milk collection, fixed time interval between consecutive milking and hind quarter secure (Table 7). As indicated in Table 8 the 70.77 per cent of the respondents conveyed their opinion regarding training needs about feeding management practices of animals as most needed followed by 22.88 percent respondents as needed while 8.11 percent as not important, as reported by Pharate et al., (2010). This might be because of their will to know the ways to enhance yield through proper feeding and balance feeding at cheaper rate which is the key to progress in this dairy enterprise particularly when effective cost of feed is increasing day by day, with not so much corresponding increase in milk rates.

Majority of the farmers $(54.88 \%)$ had perceived their training needs as most needed in health care and management practices whereas 27.22 per cent expressed it as needed while 17.88 per cent respondents expressed it as not needed. Majority of the farmers expressed their training needs about health care and management practices aspects as most needed, might be because of lack of technical knowledge about health and clinical aspects, heavy economic losses because of diseases and unavailability of timely veterinary services in remote and rural areas. In emergency situations this findings are supported by Patil et al., (2009). In housing management practices 72.5 per cent respondents were found to convey their training need as most needed followed by needed (22.75\%) and not needed (5.5\%). Regarding general management practices 56.8 per cent respondents were found to convey their training needs as most needed followed by needed (33\%) and not needed (10.22\%).

As regards information about nutritional management of animal majority of the respondents $(60.75 \%)$ opined their training needs as most needed, 22.25 per cent of the respondents as needed while 17 per cent expressed it as not needed. In reference to breeding management practices of animals 29 per cent of the respondents expressed their training needs as most needed, while majority of the respondents (45\%) as needed whereas 26 per cent respondents as not needed. 
Table.1 Distribution of feeding practices and training needs in percentage

\begin{tabular}{|c|c|c|c|c|}
\hline S1. No. & Categories & \multicolumn{3}{|c|}{ Training needs (\%) } \\
\cline { 3 - 5 } & MN (Most & $\begin{array}{c}\text { N } \\
\text { (Needed) }\end{array}$ & $\begin{array}{c}\text { NN (Not } \\
\text { needed) }\end{array}$ \\
\hline $\mathbf{1 .}$ & Dry matter intake & 83 & 13 & 04 \\
\hline $\mathbf{2 .}$ & $\begin{array}{c}\text { Balanced ration and its } \\
\text { importance }\end{array}$ & 96 & 04 & 00 \\
\hline $\mathbf{3 .}$ & Green fodder feeding & 66 & 19 & 15 \\
\hline $\mathbf{4 .}$ & Colostrums feeding & 57 & 10 & 33 \\
\hline $\mathbf{5 .}$ & Advantages of colostrums & 68 & 13 & 19 \\
\hline $\mathbf{6 .}$ & feeding & & & \\
\hline $\mathbf{7 .}$ & Drinking water & 72 & 24 & 06 \\
\hline $\mathbf{8 .}$ & Milch animal feeding & 64 & 36 & 00 \\
\hline $\mathbf{9 .}$ & Pregnant animal feeding & 57 & 43 & 00 \\
\hline
\end{tabular}

Table.2 Distribution of health care and management practices and training needs in percentage

\begin{tabular}{|c|l|c|c|c|}
\hline $\begin{array}{r}\text { Sl. } \\
\text { No. }\end{array}$ & \multicolumn{1}{|c|}{ Categories } & \multicolumn{3}{|c|}{ Training needs (\%) } \\
\cline { 1 - 4 } & & $\begin{array}{c}\text { MN (Most } \\
\text { needed }\end{array}$ & $\begin{array}{c}\text { N } \\
\text { (Needed) }\end{array}$ & NN (Not needed) \\
\hline $\mathbf{1 .}$ & Common infectious diseases & 82 & 03 & 15 \\
\hline $\mathbf{2 .}$ & Vaccination schedule & 65 & 15 & 20 \\
\hline $\mathbf{3 .}$ & Deworming schedule & 61 & 19 & 20 \\
\hline $\mathbf{4 .}$ & Parasite control & 56 & 29 & 15 \\
\hline $\mathbf{5 .}$ & Floor during parturition & 36 & 47 & 17 \\
\hline $\mathbf{6 .}$ & Management after parturition & 44 & 39 & 17 \\
\hline 7. & Management before parturition & 50 & 34 & 16 \\
\hline $\mathbf{8 .}$ & Precaution during pregnancy & 60 & 15 & 25 \\
\hline $\mathbf{9 .}$ & Adverse environment protection & 40 & 44 & 16 \\
\hline
\end{tabular}

Table.3 Distribution of housing management and training needs in percentage

\begin{tabular}{|c|c|c|c|c|}
\hline Sl. & Categories & \multicolumn{3}{|c|}{ Training needs (\%) } \\
\cline { 3 - 5 } No. & & MN & N & NN \\
\hline 1. & Shed cleaning & 70 & 24 & 06 \\
\hline 2. & Principles of housing & 75 & 25 & 05 \\
\hline
\end{tabular}


Table.4 Distribution of general management practices and training needs in percentage

\begin{tabular}{|c|c|c|c|c|}
\hline \multirow{2}{*}{$\begin{array}{l}\text { Sl. } \\
\text { No. }\end{array}$} & Categories & \multicolumn{4}{|c|}{ Training needs (\%) } \\
\cline { 2 - 5 } & MN & N & NN \\
\hline $\mathbf{1 .}$ & Pregnant animal care & 47 & 38 & 15 \\
\hline $\mathbf{2 .}$ & Before and after parturition & 50 & 35 & 15 \\
\hline $\mathbf{3 .}$ & Calf care & 60 & 40 & 00 \\
\hline $\mathbf{4 .}$ & Navel cord cutting & 57 & 32 & 11 \\
\hline $\mathbf{5 .}$ & Hygienic milk production & 70 & 20 & 10 \\
\hline
\end{tabular}

Table.5 Distribution of nutritional management and training needs in percentage

\begin{tabular}{|c|l|c|c|c|}
\hline \multirow{2}{*}{$\begin{array}{c}\text { Sl. } \\
\text { No. }\end{array}$} & \multicolumn{1}{|c|}{ Categories } & \multicolumn{3}{|c|}{ Training needs (\%) } \\
\cline { 2 - 5 } & & MN & N & NN \\
\hline 1. & Proper feeding at different age groups & 82 & 15 & 03 \\
\hline $\mathbf{2 .}$ & Importance of mineral mixture in feed & 51 & 19 & 30 \\
\hline $\mathbf{3 .}$ & Importance of colostrums feeding & 52 & 31 & 17 \\
\hline $\mathbf{4 .}$ & Importance of hygienic feeding & 58 & 24 & 18 \\
\hline
\end{tabular}

Table.6 Distribution of breeding management and training needs in percentage

\begin{tabular}{|c|l|c|c|c|}
\hline \multirow{2}{*}{$\begin{array}{c}\text { Sl. } \\
\text { No. }\end{array}$} & \multicolumn{1}{|c|}{ Categories } & \multicolumn{3}{|c|}{ Training needs (\%) } \\
\cline { 2 - 4 } & & MN & N & NN \\
\hline 1. & Importance of A.I & 54 & 19 & 27 \\
\hline 2. & Gestation period & 07 & 47 & 46 \\
\hline 3. & Heat detection & 12 & 62 & 26 \\
\hline $\mathbf{4 .}$ & Regular pregnancy diagnosis & 49 & 30 & 21 \\
\hline $\mathbf{5 .}$ & Signs of parturition & 23 & 68 & 09 \\
\hline
\end{tabular}

Table.7 Distribution of milking practices and training needs in percentage

\begin{tabular}{|c|l|c|c|c|}
\hline Sl. & \multicolumn{1}{|c|}{ Categories } & \multicolumn{3}{|c|}{ Training needs (\%) } \\
\cline { 2 - 4 } No. & & MN & N & NN \\
\hline 1. & Hind quarter wash & 38 & 28 & 34 \\
\hline $\mathbf{2 .}$ & Grooming during milking & 10 & 45 & 45 \\
\hline $\mathbf{3 .}$ & Hind quarter secure & 5 & 51 & 44 \\
\hline $\mathbf{4 .}$ & Hand washing & 27 & 44 & 29 \\
\hline $\mathbf{5 .}$ & Udder washing & 79 & 16 & 05 \\
\hline $\mathbf{6 .}$ & First strip milk collection & 41 & 50 & 09 \\
\hline $\mathbf{7 .}$ & fixed time interval between consecutive milking & 45 & 49 & 06 \\
\hline $\mathbf{8 .}$ & Concentrate offered during milking & 16 & 75 & 09 \\
\hline
\end{tabular}


Table.8 Distribution of respondents according to their overall training needs in buffalo farming practices

\begin{tabular}{|l|l|l|l|l|l|l|l|}
\hline Sl. & Training area & \multicolumn{2}{|l|}{ Most needed } & \multicolumn{2}{l|}{ Needed } & \multicolumn{2}{l|}{ Not needed } \\
\hline No & & Percent & Rank & Percent & Rank & Percent & Rank \\
\hline 1. & Feeding practices & 70.77 & II & 20.88 & VII & 8.11 & VI \\
\hline 2. & $\begin{array}{l}\text { Health care and } \\
\text { management practices }\end{array}$ & 54.88 & V & 27.22 & IV & 17.88 & III \\
\hline 3. & Housing management & 72.50 & I & 22.00 & VI & 5.50 & VII \\
\hline 4. & General management & 56.80 & IV & 33 & III & 10.20 & V \\
\hline 5. & Nutritional management & 60.75 & III & 22.25 & V & 17 & IV \\
\hline 6. & Breeding management & 29 & VII & 45 & I & 26 & I \\
\hline 7. & Milking practice & 32.60 & VI & 44.75 & II & 22.62 & II \\
\hline
\end{tabular}

The results revealed that there is a need for conducting more number of needs based and well tailored training programme suited to buffalo farmers which would in turn help them to have more extension contact. Thus in the present study among seven broader areas of training, respondents expressed their willingness to have most needed training in the descending order as housing management, feeding management practices, nutritional management, general management, health care and management practices, clean milk production practices and breeding management practices. The results of the study help the extension agencies to develop suitable training programme for the buffalo farmers to improve their productivity and run buffalo farming successfully which in turn increases farmers life style.

\section{References}

Anonymous., 2014. Annual Report 2013-14, Department of Animal Husbandry, Dairying and Fisheries, Govt. of India. New Delhi.
Davis, J. and Rylance, C. 2005. Addressing poverty through local economic and enterprise development: A Review of Conceptual Approaches and Practices. Working Paper 3, National Resources Institute.

Lyunton, R.P. and Pareek, U. 1990. Training for Development. New Delhi: Vistaar Publications.

Meena, B.L., 1994. A study on adoption and training needs of tribal farm women in improved dairy farming practices of Sawai Madhopur, Rajasthan. M.Sc. (Agri), Thesis submitted to NDRI, Karnal.

Patil, A.P., Gawande, S.H., Gobade, M.R. and Nandc, M.P, 2009. Training needs of dairy farmers in Nagpur district. Veterinary world, 2(5): 187-190.

Pharate, D.N., Sindhe, S.B and Sonawane, H.P, 2010. Training needs and participation of farmers in dairy management. Agricultural update, 5(3\& 4): 271-273.

Sah, U., Kumar, S. and Fulzele, R.M, 2002. Perceived needs of dairy farmers and farm women to improve dairy farming in India: An overview. Agric. Rev., 23(1): 65-70.

\section{How to cite this article:}

Ankush Bharti, Debasis Ganguli, Arunasis Goswami and Pankaj Kumar. 2018. Training Needs of Buffalo Farmers in Madhepura District of Bihar Int.J.Curr.Microbiol.App.Sci. 7(07): 2607-2613. doi: https://doi.org/10.20546/ijcmas.2018.707.305 